\title{
Correlation of Contraction Strength between Gastrocnemius Soleus Muscle and Levator Ani Muscle among Individuals with Uterine Prolapse
}

\author{
Sri Kusumawati
}

\begin{abstract}
Introduction: Elderly or menopause is one of the uterine prolapses' predisposition; however, not every patients with the menopause suffer from uterine prolapses. It is presumed that it is caused by differences of levator ani muscle strength between patients with and without uterine prolapses. Weak levator ani contraction strength is an initial predisposition of uterine prolapses' occurrence; thus, researchers assumed that there is an overall skeletal muscle strength weakness among patients with uterine prolapses. The overall skeletal muscle strength was represented by the gastrocnemius soleus muscle.

Materials and methods: This study aimed to compare gastrocnemius soleus contraction strength between women with and without an uterine prolapse. This study is a comparative, observational analytic study with a cross-sectional approach.

Results: The subjects of this study were 48 women divided into two groups: (i) menopause women with a pelvic organ prolapse and (ii) those without a pelvic organ prolapse. Measurements were done on pelvic floor muscle contraction strength (Peritron ${ }^{\mathrm{TM}}$ perineometer) and gastrocnemius soleus muscle contraction strength (hand-held dynamometer).

Discussion: This study was conducted at Dr Hasan Sadikin General Hospital Bandung during September-October 2016. Statistical analysis reported that the $p$ value results on a perinometer and a hand-held dynamometer were below 0.05 ( $p$ value $<0.05$ ) for both groups. A correlation coefficient $(r)$ of 0.519 was classified as the moderate category, with significant correlation results due to a $p$ value of $0.001, a<0.05$. It is concluded that there was a significant correlation between levator ani and gastrocnemius soleus muscle contraction strength among post-menopause uterine prolapse patiets.

Conclusion: Gastrocnemius soleus skeletal muscle contraction strength among women with POP was lesser compared with women without POP, and there was a correlation between pelvic floor muscle contraction strength and gastrocnemius soleus skeletal muscle contraction strength. Keywords: Gastrocnemius soleus skeletal muscle contraction strength, Hand-held dynamometer, Pelvic floor muscle contraction strength, Pelvic organ prolapse, Peritron ${ }^{\mathrm{TM}}$ perineometer.

Journal of South Asian Federation of Menopause Societies (2019): 10.5005/jp-journals-10032-1171
\end{abstract}

\section{INTRODUCTION}

Uterine prolapse is an abnormality occured owing to weakening of pelving supporting organs such as levator ani neuromuscular tissue, ligaments, and fascia. Levator ani muscle make a concaveshaped plate, actively maintaining continency by supporting pelvic organ and pulling mechanisms cranioanteriorly during contraction. A study conducted in USA had revealed that uterine prolapses was quite common, with a prevalence of $14.2 \%$ among general population, and especially among multiparous and menopaused women with prevalence of more than $50 \% .^{1-4}$

The weakening of levator ani muscle was relatively common and increasing following age and parity. However, not every individual with menopause suffer from uterine prolapses, and it is presumed that it is caused by the differences of levator ani muscle strength between individuals with and without uterine prolapses, while levator ani muscle weakening was frequently linked to sarcopenia., ${ }^{1,4}$

Currently, a study conducted by National Health and Nutrition Examination Survey found that uterine prolapse occurs in a variety of ages. ${ }^{5}$ Weakened levator ani muscle is an initial predisposition toward uterine prolapse; thus, it is pressumed that weakening of the overall skeletal muscle strength existed among patients with uterine prolapses. This study aimed to compare other skeletal
Department of Obstetrics and Gynecology, Faculty of Medicine, Universitas Padjadjaran/Dr Hasan Sadikin General Hospital Bandung, Bandung, West Java, Indonesia

Corresponding Author: Sri Kusumawati, Department of Obstetrics and Gynecology, Faculty of Medicine, Universitas Padjadjaran/Dr Hasan Sadikin General Hospital Bandung, Bandung, West Java, Indonesia, e-mail: jurnalwati@gmail.com

How to cite this article: Kusumawati S. Correlation of Contraction Strength between Gastrocnemius Soleus Muscle and Levator Ani Muscle among Individuals with Uterine Prolapse. J South Asian Feder Menopause Soc 2019;7(1):1-4.

Source of support: Nil

Conflict of interest: None

muscle, represented by gastrocnemius soleus muscle, and levator ani muscle between individuals with and without an uterine prolapse.

\section{Materials and Methods}

This study is an analytic observational study with a cross-sectional approach, aiming to analyze a comparison of contraction strength 
between levator ani muscle and gastrocnemius soleus muscle between individual with and without uterine prolapses. This study was conducted at the Department of Obstetrics and Gynecology, and Department of Physical Health and Rehabilitation, Dr Hasan Sadikin General Hospital Bandung, during the period of SeptemberOctober 2016. Ethical Clearance had been reviewed by Health Research Ethics Committee Universitas Padjadjaran. Permission had been secured from all participating respondents. Confidentiality is maintained during and after the study.

The subjects of this study are women with and without uterine prolapses living in Bandung City and Bandung Regency region volunteered to participate. Subjects with a uterine prolapse were patients visiting Gynecology Clinic, Dr Hasan Sadikin General Hospital, while subjects without a uterine prolapse were inhabitants nearby Dr Hasan Sadikin General Hospital Bandung with homogeneous characteristics identical to those of the subjects with a uterine prolapse. A consecutive sampling method was used until a minimum sampling size was reached. Patients with unstable vital signs and poor general apprearance were excluded from participating in this study. Patients underwent treatment for other established diagnosis of diseases such as diabetes mellitus, stroke, and any type of neuropathy were also excluded from this study. Exclusion was also applied on patients who used hormonal contraception or other hormonal therapy during the previous 3-6 months before the study.

Contraction strength of the gastrocnemius soleus muscle was measured by a hand-held dynamometer. Subjects were comfortably pronated with maximum plantar flexion, and the device was located in metatarsal with the indicator pointing on zero. Subjects were maintained at a metatarsal position with gradually increasing resistance, with a maximum length of 3-5 seconds without any joint movements. An average of three measurements in the dominant limb were noted as the maximum contraction strength of the gastrocnemius soleus muscle. ${ }^{6}$

Contraction strength of the levator ani muscle was measured by a perineometer ${ }^{\mathrm{TM}}$ in Gynecology Clinic, Dr Hasan Sadikin General Hospital Bandung. Subjects were in a litothomy position with a distance of $30 \mathrm{~cm}$ between two knees. Bladders were emptied before the measurement. A perineometer sensor wrapped with a condom was turned on, calibrated to zero, and were inserted into the vagina until the length of the sensor became $1-2 \mathrm{~cm}$. The subjects were then asked to contract the levator ani muscle identical when they tried to hold the urinary stream. Measurements in the perineometer were conducted with the $\mathrm{CmH}_{2} \mathrm{O}$ unit.

Data acquired were analyzed by SPSS for Windows (version 21). Normality tests for numeric variables were executed by the Shapiro-Wilk test, followed by a paired $t$ test or Mann-Whitney test, accordingly. Chi-square tests were used for analyzing categoric variables, with Exact Fisher test or Kolmogorov-Smirnov test being used alternately. ANOVA or Krusskall-Wallis tests were used accordingly to find the differences of numeric and categoric data among the four groups. Hypothetical testing was done by a paired $t$ test or Wilcoxon test, accordingly.

\section{Results}

As much as 48 subjects (24 individuals with uterine prolaps and 24 individual without uterine prolaps) volunteered to participate in this study. Subjects were then classified into several categories according to age, parity, BMl, and physical activity.

As shown in Table 1, both group had a bigger proportion of subjects with the age of $>50$ years. The mean age for the uterine
Table 1: Subjects' characteristics according to age, parity, BMI, and physical activity

\begin{tabular}{|c|c|c|c|}
\hline \multirow[b]{2}{*}{ Variables } & \multicolumn{2}{|c|}{ Group } & \multirow[b]{2}{*}{ pvalue } \\
\hline & $\begin{array}{l}\text { With uterine pro- } \\
\text { lapse }(n=24)\end{array}$ & $\begin{array}{l}\text { Without uterine } \\
\text { prolapse }(n=24)\end{array}$ & \\
\hline Age & & & 0.303 \\
\hline$<50$ years old & $4(16.7 \%)$ & $7(29.2 \%)$ & \\
\hline$>50$ years old & $20(83.3 \%)$ & $17(70.8 \%)$ & \\
\hline Age & & & 0.147 \\
\hline Mean \pm SD & $56.208 \pm 8.016$ & $53.1667 \pm 6.119$ & \\
\hline Median & 8.016 & 52.500 & \\
\hline Range (min-max) & $38.00-70.00$ & $44.00-6.00$ & \\
\hline Parity & & & 0.624 \\
\hline$<\mathrm{P} 3$ & $7(29.2 \%)$ & $7(29.2 \%)$ & \\
\hline$>\mathrm{P3}$ & 17 (70.8\%) & $17(70.8 \%)$ & \\
\hline BMI & & & 1.000 \\
\hline Normoweight & $7(29.2 \%)$ & $7(29.2 \%)$ & \\
\hline Overweight & $13(54.2 \%)$ & 13 (54.2\%) & \\
\hline Obese & $4(16.7 \%)$ & $4(16.7 \%)$ & \\
\hline Physical activity & & & 0.624 \\
\hline Yes & $7(29.2 \%)$ & $7(29.2 \%)$ & \\
\hline No & $17(70.8 \%)$ & 17 (70.8\%) & \\
\hline
\end{tabular}

Note: Categorical data were analyzed by a Chi-square test.

Significance were noted with a $p$ value of $<0.05$

Table 2: A comparison of skeletal muscle contraction strength between gastrocnemius soleus and levator ani muscle, adjusted with the uterine prolapse state

\begin{tabular}{llll}
\hline & \multicolumn{2}{c}{ Group } & \\
\cline { 2 - 3 } Variable & $\begin{array}{l}\text { With uterine } \\
\text { prolapse }(n=24)\end{array}$ & $\begin{array}{l}\text { Without uterine } \\
\text { prolapse }(n=24)\end{array}$ & $p$ value \\
\hline $\begin{array}{l}\text { Perineometer } \\
\text { Mean } \pm \text { SD }\end{array}$ & $25.654 \pm 6.858$ & $44.312 \pm 12.4063$ & $0.001^{* *}$ \\
$\begin{array}{l}\text { Hand held } \\
\text { Mean } \pm \text { SD }\end{array}$ & $9.1167 \pm 1.5190$ & $13.662 \pm 1.1146$ & $0.001^{* *}$ \\
\hline
\end{tabular}

Note: $p$ values shown were calculated by a paired $t$ test

prolapse group and no uterine prolapse group was $56.208 \pm$ 8.016 years old and $53.1667 \pm 6.119$ years old, respectively. Both groups had a bigger proportion of high parity rate (>P3), with each group shared 17 subjects out of the 24 subjects in each group. When adjusted with their body weight, both groups were predominated by overweight subjects, followed by normoweight subjects and obese subjects with a proportion of 13,7 , and 4, respectively. The Chi-square test showed no significance on all sociodemographic variables; so it was concluded that both groups were homogeneous and comparable.

Table 2 showed a comparison of contraction strength between the levator ani muscle and the gastrocnemius soleus muscle. Results were adjusted by age, parity, BMI, and physical activity. The mean of the levator ani muscle contraction strength on the group with uterine prolapse and that without uterine prolapse were $25.654 \pm 6.858$ and $44.312 \pm 12.4063$, respectively. While on the other hand, hand-held dynamometer results showed a mean of contraction strength of $9.1167 \pm 1.5190$ among those in the group with uterine prolapse and $13.662 \pm 1.1146$ among those in the group without uterine prolapse. 
Table 3: Correlation between levator ani muscle contraction strength and gastrocnemius soleus contraction strength among postmenopause patients

\begin{tabular}{lll}
\hline & $R$ & $P$ \\
\hline $\begin{array}{l}\text { Levator ani muscle and gastrocnemius soleus muscle } \\
\text { contraction strength }\end{array}$ & 0.519 & 0.001
\end{tabular}

Note: Numeric data were analyzed by a 2-tailed Pearson test

Table 4: Correlarion between levator ani muscle contraction strength and gastrocnemius soleus contraction strength, adjusted with the occurence of pelvic organ prolapse

\begin{tabular}{llllll}
\hline & \multicolumn{3}{c}{$P O P$} & & \multicolumn{2}{c}{ Non-POP } \\
\cline { 2 - 3 } \cline { 5 - 6 } & $R$ & $P$ & & $R$ & $P$ \\
\hline $\begin{array}{l}\text { Contraction strength of gastrocnemius } \\
\text { soleus muscle }\end{array}$ & 0.473 & 0.019 & & 0.494 & 0.014 \\
$\begin{array}{l}\text { Contraction strength of levator ani } \\
\text { muscle }\end{array}$ & 0.473 & 0.019 & & 0.494 & 0.014 \\
\hline
\end{tabular}

Note: Numerical data were analyzed by a 2-tailed Pearson test

Both levator ani muscle and gastrocnemius soleus muscle contraction strength showed significancy with $p$ value of 0.001 .

As shown as in Table 3, correlation coefficient showed $r$ of 0.519 , and it showed moderate category with $p$ value of 0.001 . It is concluded that there were significant, moderate correlations between the levator ani muscle and gastrocnemius soleus muscle contraction strength among post-menopause patients.

Table 4 revealed that there were $r$ of 0.473 , or categorized as "moderate", with significance and a $p$ value of 0.019 among post menopause patients with a pelvic organ prolapse. On the other hand, $r$ among postmenopause individuals without a pelvic organ prolapse were 0.494 , or categorized as "moderate", with significancy and $p$ value of 0.014 . It is concluded that there were significant differences on levator ani and gastrocnemius soleus muscle contraction strength on both the POP and the non-POP group.

\section{Discussion}

This study tried to analyze age, parity, BMI, and physical activity since these characteristics are risk factors contributing to levator ani muscle weakness; thus these factors might be confounding in this study. This study included post-menopause women with the age ranging between 44 years and 70 years. Several studies stated that aging increased the risk of levator ani weakening owing to decreasing muscle mass initiated at the age of 40 , and the reduction will be gradually becoming significant at the age of $60 .^{7-9}$ However, another study involed 375 women, proving that there were only weak correlation between subjects age and levator ani muscle strength $(r=0.25 p<0.01) .{ }^{10}$ Other characteristic analyzed in this study is parity. Several studies stated that high parity also raised the risk of weakening levator ani muscle because of rising weight burden during pregnancy and trauma during parturition. ${ }^{9,11,12}$ Obesity was also presumed to be contributing to levator ani weakness, as several studies stated that obesity had a significant relation with levator ani muscle contraction strength. ${ }^{9}$ However, other research showed no significance between obesity and levator ani muscle contraction strength. ${ }^{13}$ Physical activity was also considered as confounding, as more physical activity frequency raise the overall skeletal muscle contraction strength; thus, levator ani contraction strength should also rise. ${ }^{14}$
Normal levator ani contraction was maintained by type-I action (slow twitch) as it was dominantly found in the levator ani muscle. This activity maintain the closure of urogenitalis hiatus by pulling the distal part of the urethra, vagina, and anus into the pubic bone. On the other hand, type-Il action (fast twitch) allows the levator ani to contract by reflex, in which it is usually caused by a sudden increase in abdominal pressure. Levator ani is a complex muscle consisted by several muscular components with different origin and insertion; thus, it has a different purposive function. ${ }^{15}$ On the other hand, soleus was known as predominated by type I muscle fiber with a proportion of $80-96 \%$, and gastrocnemius was known as a combination of type I and type II muscle fibers, with a tendency of type I muscle fiber with a proportion of $50-76 \%{ }^{16-20}$ In this study, it was revealed that the correlation coefficient ( $r$ ) was 0.473 , or classified as "moderate" with a $p$ value of 0.019 . It was concluded that there were moderate and significant correlations between the levator ani muscle and gastrocnemius soleus muscle contraction strength among postmenopause patients with a pelvic organ prolapse, in which it might be caused by similarities in the muscle fiber type. ${ }^{3,16-21}$ This study revealed gastrocnemius soleus muscle contraction strength among the group with pelvic organ prolapse and that without pelvic organ prolapse as $9.4625 \pm 1.9613 \mathrm{~kg}$ and $13.6417 \pm 1224 \mathrm{~kg}$, respectively. On the other hand, this study also revealed the levator ani muscle contraction strength among group with pelvic organ prolapse and without pelvic organ prolapse as $25.6542 \pm 6.8589 \mathrm{CmH}_{2} \mathrm{O}$ and $43.3708 \pm 12.6604 \mathrm{CmH}_{2} \mathrm{O}$, respectively, after adjusted by age, parity, $\mathrm{BMI}$, and physical activity, as those four characteristics were known as confounding in previous studies. $^{7-14}$ There were no previous study regarding the comparison of gastrocnemius soleus and levator ani muscle contraction strength. It is concluded that there were moderate and significant correlations between levator ani and gastrocnemius soleus muscle contraction strength, as this study revealed an $r$ value of 0.519 and a $p$ value of 0.001 .

Both measurements of muscle contraction strength showed a higher contraction strength mean demonstrated by the group of individuals without a pelvic organ prolapse. When it was adjusted with the occurence of pelvic organ prolapse, the group of individuals with a pelvic organ prolapse showed an $r$ of 0.473 , categorized as "moderate" correlation, and a $p$ value of $0.019, \alpha<0.05$. On the other hand, the group of individuals without pelvic organ prolapse also showed an $r$ of 0.494 , categorized as "moderate", with a $p$ value of 0.014 . It is concluded that there were moderate and significant correlations between levator ani and gastrocnemius soleus muscle contraction strength on both groups.

Muscular strength may be defined as the maximum ability of muscle to hold forces of weight. The weakening of levator ani muscle depends on innervation, strength of ligaments, and strength of the fascia. ${ }^{22}$ However, there were no clear explainations regarding race predisposition and genetic component available recently; as current research had shown a difference in frequency revealed in USA. ${ }^{4,23}$ Other studies currently shown the correlation of vitamin D deficiency. ${ }^{5}$ This study was conducted in Indonesia, where the genetic background was relatively homogeneous, and no vitamin $\mathrm{D}$ measurement was conducted; thus it might only revealed the existence of overall skeletal muscle contraction strength differences, without revealing the underlying mechanisms.

This study also had other limitations. Even if confounding had already been on used to adjust the patients; however, control group might contribute to a better analysis of contraction strength measurements. On the other hand, there was no reference value 
for levator ani and gastrocnemius soleus muscle contraction strength among general population worldwide and among general population in Indonesia; thus objective reduction of muscle contraction strength among general population may not be correctly established. Other limitations are the limited number of research subjects used and a considerably long period of time involved (2014-2016) in this study.

\section{Conclusion}

Further studies regarding gastrocnemius soleus skeletal muscle strength might be needed to adjust it relations with age, parity, BMI, and physical activity. In addition, further studies regarding the comparison of preoperative gastrocnemius soleus and pelvic floor contraction muscle strength with a cohort approach would be considered better.

\section{References}

1. Badalian SS, Rosenbaum PF. Vitamin D and pelvic floor disorders in women: results from the National Health and Nutrition Examination Survey. Obstet Gynecol 2010;115(4):795-803. DOI: 10.1097/ AOG.0b013e3181d34806.

2. Berek JS. Berek and Novak's Gynecology. Wolters Kluwer Health; 2012.

3. Burkman RT. Berek \& Novak's Gynecology. JAMA 2012;308(5):516-517. DOI: 10.1001/jama.308.5.516.

4. Danforth DN, Gibbs RS. Danforth's obstetrics and gynecology. Lippincott Williams \& Wilkins; 2008.

5. Pludowski P, Holick MF, Pilz S, et al. Vitamin D effects on musculoskeletal health, immunity, autoimmunity, cardiovascular disease, cancer, fertility, pregnancy, dementia and mortality-a review of recent evidence. Autoimmun Rev 2013;12(10):976-989. DOI: 10.1016/j.autrev.2013.02.004.

6. Hislop H, Avers D, Brown M. Daniels and Worthingham's muscle testing: Techniques of manual examination and performance testing. Elsevier Health Sciences; 2013.

7. Wei JT, De Lancey JO. Functional anatomy of the pelvic floor and lower urinary tract. Clin Obstet Gynecol 2004;47(1):3-17. DOI: 10.1097/00003081-200403000-00004.

8. Ratna Amalia Saanin BHP. Adhi Pribadi. Perbandingan Edukasi Latihan Kegel antara Metode Verbal dan Metode Percobaan Latihan Untuk Meningkatkan Tonus Basal dan Kontraksi Maksimal Levator Ani. Bandung: Universitas Padjadjaran; 2016.

9. MacLennan AH, Taylor AW, Wilson DH, et al. The prevalence of pelvic floor disorders and their relationship to gender, age, parity and mode of delivery. BJOG 2000;107(12):1460-1470. DOI: 10.1111/j.14710528.2000.tb11669.x.

10. Weemhoff M, Shek KL, Dietz HP. Effects of age on levator function and morphometry of the levator hiatus in women with pelvic floor disorders. Int Urogynecol J Pelvic Floor Dysfunct 2010;21(9):1137-1142. DOI: 10.1007/s00192-010-1150-0.

11. Nygaard I, Barber MD, Burgio KL, et al. Prevalence of symptomatic pelvic floor disorders in US women. Jama 2008;300(11):1311-1316. DOI: 10.1001/jama.300.11.1311.

12. Kepenekci I, Keskinkilic B, Akinsu F, et al. Prevalence of pelvic floor disorders in the female Prolapsus uteriulation and the impact of age, mode of delivery, and parity. Dis Colon Rectum 2011;54(1):85-94. DOI: 10.1007/DCR.0b013e3181fd2356.

13. Lubis DL. Kekuatan Otot Dasar Panggul Pada Wanita Pasca Persalinan Normal Dan Pasca Seksio Sesarea Dengan Perineometer; 2009.

14. Rahajeng R. Efek Latihan Kegel pada Kekuatan Otot Dasar Panggul Ibu Pasca Persalinan. Jurnal Kedokteran Brawijaya 2013;26(2):120-123. DOI: 10.21776/ub.jkb.2010.026.02.11.

15. Corton MM. Anatomy of pelvic floor dysfunction. Obstet Gyn Clin N Am 2009;36(3):401-419. DOI: 10.1016/j.ogc.2009.09.002.

16. Beardsley C. Just "Get strong is wrong". Muscle fiber type. strength training; 2016 September 18th 2016.

17. Johnson MA, Polgar J, Weightman D, et al. Data on the distribution of fibre types in thirty-six human muscles: an autopsy study. J Neurol Sci 1973;18(1):111-129. DOI: 10.1016/0022-510X(73)90023-3.

18. Dahmane R, Djordjevič $S$, Smerdu V. Adaptive potential of human biceps femoris muscle demonstrated by histochemical, immunohistochemical and mechanomygraphical methods. Med Biol Eng Comput 2007;45(3):323-324. DOI: 10.1007/s11517-0060146-x.

19. Edgerton VR, Smith J, Simpson D. Muscle fibre type Prolapsus uteriulations of human leg muscles. Histochem J 1975;7(3):259-266. DOI: 10.1007/BF01003594.

20. Keh-Evans L, Rice C, Noble E, et al. Comparison of histochemical, biochemical and contractile properties of triceps surae of trained aged subjects. Can J Aging 1992;11(04):412-425. DOI: 10.1017/ S0714980800006929.

21. Ganong WF. Buku ajar fisiologi kedokteran. Edisi 2008;22:155-156.

22. Messelink B, Benson $T$, Berghmans $B$, et al. Standardization of terminology of pelvic floor muscle function and dysfunction: report from the pelvic floor clinical assessment group of the International Continence Society. Neurourol Urodyn 2005;24(4):374. DOI: 10.1002/ nau.20144.

23. Downing KT. Uterine prolapse: from antiquity to today. Obstet Gynecol Int 2011;2012:649459. DOI: 10.1155/2012/649459. 